\title{
Textual Complexity of Standard Conditions used in the Construction Industry
}

Raufdeen Rameezdeen, (University of South Australia, Australia)

Anushi Rodrigo, (University of Northumbria, UK)

\begin{abstract}
Clearly written communication aids the understanding of construction contracts, resulting in less disputation. Past research, using opinion surveys rather than objective criteria, shows that construction contracts lack clarity and standard forms have become complex over time. The study outlined in this paper uses three objective measures of clarity developed by linguists to establish the readability of construction contracts. In addition, thirty industry professionals participated in a Cloze Test which measured the level of comprehension of clauses concerning disputes. The study verifies that contract conditions are very difficult to read, with college level reading skills needed to comprehend half of the clauses. However, the hypothesis that standard forms have become complex over time was not supported by the study. The study establishes a linear relationship between readability and comprehension, proving the hypothesis that improved readability increases the comprehension of a contract clause.
\end{abstract}

Keywords: Readability, Clarity, Comprehension, Construction, Contract

\section{Introduction}

Successful delivery of a construction project depends on proper communication between the parties (Emmitt and Gorse 2003). A contract stipulates privileges and commitments as well as procedures to be followed by the contracting parties (Ndekugri et al. 2007). A good contract develops an acceptable level of communication ensuring smooth functioning of a project (Kennedy et al. 1997). Lawyers and arbitrators are not the primary users of a contract but the parties to a project and the contract administrators. Therefore, these non-legal professionals' comprehension is fundamental for contract performance (Haapio 2011). According to Smith and Taffler (1992), the usefulness of a narrative is decided by the intricacy of the text (readability) and the ability of users to capture its meaning (comprehension). Furthermore, if the message intended by the writer is to be successfully conveyed, the receiver must be able to both read and understand it (Russell 2007). For construction-related technical communication, such as conditions of contract, it is obvious that both readability and comprehension are vital for determining the contract's effectiveness in practice (Broome \& Hayes 1997; Chong et al. 2011). According to Rameezdeen and Rajapakse (2007), when the readability of a contract clause is high, its comprehension by different readers is also high.

As readability and comprehension of contract conditions can improve communication between the parties, an examination of whether contract conditions can be easily read and understood is warranted. While the theme of readability is a mainstream research area in linguistics, research dealing with readability in the context of contract interpretation is minimal. Prior research, using opinion surveys, shows that contract conditions used in construction lack clarity (Broome \& Hayes 1997; Bunni 2003; Chong \& Zin 2010). Studies also show that standard forms have become complex over time (Bunni 2003). However, these past studies have not used objective criteria to support their claim. In addition, they do not make it clear whether clarity can improve comprehension. Given that the cost of disputes to the construction industry is enormous (Jergeas \& Hartman 1994) a focus on clarity of 
contract conditions may help partly bridge this gap in understanding. In that context, this paper reports the findings of a research study carried out on the clarity of contract conditions and its relationship to comprehension.

\section{Clarity of Contract Conditions}

Broom and Hayes (1997) note that standard forms of contract used in construction are plagued with many problems; lack of clarity is the most significant. By clarity, the authors mean the design and layout of the whole contract document, as well as the use and order of words within a sentence (Broom \& Hayes 1997, p. 255). Bubshait and Almohawis (1994, p. 134) define clarity as 'the ease with which the language of the general conditions can be understood, and the absence of ambiguities'. According to Broome and Hayes (1997, p. 256) lack of clarity in traditional contract conditions is mainly attributable to long sentence length, poor layout and the presence of many redundant legal expressions. This contention is supported by Ali and Wilkinson (2010), Chong and Zin (2010), and Wright and Fergusson (2009). In their experiment, Masson and Waldron (1994) found that comprehension of a contract document among non-legal experts increased when redundant terms were removed or replaced, sentence structures were simplified and legal jargon were replaced by simplified terms. In order to achieve legal precision, drafters have ignored laypersons' ability to understand the language contained in these documents (Greene et al. 2012). Additionally, most of the legal jargons had derived historically from Latin or French languages and this tradition continues to prevail today (Greene et al. 2012).

Bunni (2003) is of the view that original standard forms were error-free and drafted using precise language. With later editions, the original documents were tinkered with to fill gaps in an ad hoc manner making the document more complex and ambiguous. Thus, Bunni (2003) asserts that contract forms have become more complex and difficult to read with each successive edition. According to Wright and Ferguson (2009) this process of constant revision has led to contracts causing disagreements and disputes. According to Broom and Hayes (1997) these revisions are normally carried out by committees and they are to be blamed for lack of clarity in subsequent editions.

Researchers believe that lack of clarity in contract documents can adversely affect the relationship between client and contractor by making it more adversarial (Bresnen \& Marshall 2000; Cheung \& Yiu 2006). Kennedy et al. (1997) finds this to be true between contractors and sub-contractors as well. Lack of clarity in contract conditions can even lead to disputes (Broome \& Hayes 1997; Harmon 2003; Chong \& Zin 2010). Most often an ambiguous clause may be the focal point of a dispute (Thomas et al. 1994). Thus, better interpretation and understanding of contract terms by parties would help avoid a dispute from festering (Cheung \& Yiu, 2007; Chong \& Zin, 2010). Broome and Hayes (1997) attribute interpretation errors mainly to contract clarity and legalese. Legalese may obscure the overall meaning due to unnecessary formality (Wang \& Yang 2005; Ali \& Wilkinson 2010). However, in some instances legalese helps convey a message in certain terms (Thomas et al. 1994; Candlin et al. 2002).

Legal scholars generally agree that proper drafting of standard forms could improve readability and comprehension (Valentine 1992; Ali \& Wilkinson 2010). Researchers widely believe that New Engineering Contracts (NEC) and Engineering and Construction Contracts (ECC) are clearer than other standard forms and constitute a way forward in contract drafting (Broome \& Perry 1995; Rameezdeen \& Rajapakse 2007; Wright \& Fergusson 2009). Chong and Zin (2010) propose many recommendations to improve the clarity of contract conditions; the most profound being improvement of the language structure. This reinforces the observations made in other studies which call for 'clear' and 'plain' language for contract conditions (Broome \& Hayes 1997; Rameezdeen \& Rajapakse 2007; Ali \& Wilkinson 2010). 


\section{Measures of Clarity and Comprehension}

Linguists have tried to develop measures to determine the clarity of documents. In the beginning different readability formulae were used and later alternative measures such as the texture index, transitivity index and diction scores were developed (Sydserff \& Weetman 2002). Though many new measures have evolved, readability formulae are considered to be the most suitable in measuring clarity (Glick et al. 2010). The literature provides many definitions for readability; Klare's definition - 'the ease of understanding or comprehension due to the style of writing' - is the most popular (DuBay 2004, p.3). Other definitions include McLaughlin's (1969, p.640) 'a measure of the linguistic characteristics of a text' and Calderỏn et al.'s (2006, p.49) 'the semantic and syntactic attributes of the written word'. Stamboltzis and Pumfrey (2000, p.58) consider readability to be a cognitive constructive process through which individuals make meaning. DuBay (2004, p.3) explains readability simply as what makes some texts easier to read than others.

Numerous methods are used to obtain the readability of a text. All methods rely on the complexity of words in sentences (Koo et al. 2003). Readability formulae can predict the level of difficulty of a text (Hall 2006). Some of the popular readability formulae are:

- Flesch Reading Ease Score,

- Flesch-Kincaid Grade Level,

- Simple Measure of Gobbledygook,

- Automated Readability Index,

- Spache Readability Formula,

- Coleman Liau Index,

- Gunning Fog Index,

- Raygor Estimate Graph, and

- Fry Readability Graph

Flesch Reading Ease Score (FRES) is a popular, tested and reliable formula for readability testing (Rameezdeen \& Rajapakse, 2007), being consistent and highly associated with other indices (Paz et al. 2009). FRES ranges from 0-100, where a score of 0 indicates a text that is very difficult to read, while a score of 100 is very easy to read. Table 1 provides a guide to FRES using an example of the difficulty level based on different reading grades.

\begin{tabular}{|c|c|c|}
\hline FRES & Difficulty Level & Estimated Reading Grade \\
\hline $\mathbf{0 - 3 0}$ & Very difficult & Postgraduate \\
\hline $\mathbf{3 0 - 5 0}$ & Difficult & College \\
\hline $\mathbf{5 0 - 6 0}$ & Fairly difficult & High school \\
\hline $\mathbf{6 0 - 7 0}$ & Standard & 8th to 9th Grade \\
\hline $\mathbf{7 0 - 8 0}$ & Fairly easy & 7th Grade \\
\hline $\mathbf{8 0 - 9 0}$ & Easy & 5th to 6th Grade \\
\hline $\mathbf{9 0 - 1 0 0}$ & Very easy & 3rd to 4th Grade \\
\hline
\end{tabular}

Table 1 FRES guide to comparisons of readability (Source: Rameezdeen \& Rajapakse 2007)

The drawbacks of readability formulae are well documented in the literature. Readability tests do not factor in meaning and they should not be considered perfect measures of readability (Harrison \& Bakker, 1998). A readability formula evaluates only the text that could be quantified (Orlow et al. 2003). It does not take word order or grammar into consideration (Rutherford, 2003) and neither are reader characteristics (Curtis 1998). Though there are limitations, Velez and Ashworth (2007) argue that the formulae still offer valuable predictions on readability. The popularity is mainly because they are inexpensive, objective and reliable, and can be helpful in detecting certain obvious errors such as excessive sentence length (Sydserff \& Weetman 2002). 
Comprehension is the understanding of a text and is quite different from readability (Jones 1997). Readability measures the textual complexity of a document while comprehension the reader's understanding (Jones 1997). Thus, comprehension is influenced by the reader's characteristics in addition to the textual complexity (Fanguy et al. 2004). According to the Construction-Integration model developed by Kintsch (1988), text comprehension is achieved by two levels of mental representation: firstly, extraction of information from the text: and secondly, linking it to prior knowledge on the subject. The first level involves a micro level text-driven process of establishing semantic connections between various text elements (van den Broek et al. 2005). When a text lacks clarity, the reader has to make more effort to deal with the micro level textual analysis.

Different methodologies have been used to measure comprehension with the Cloze test, developed by Wilson L. Taylor in 1953, being the most popular (Smith \& Taffler 1992). A Cloze test employs several paragraphs with words deleted and asks the respondent to fill in the gaps with appropriate words. The percentage of words correctly filled is known as the Cloze score. When the score is low, the text is considered to be difficult (Smith \& Taffler 1992). Table 2 provides an interpretation of the results of a Cloze test.

\begin{tabular}{|c|c|c|}
\hline Cloze & Comprehension level & Estimated reading level \\
\hline $\mathbf{6 0} \%-100 \%$ & Easy & Unassisted reading \\
\hline $35 \%-60 \%$ & Standard & Instructional, assisted reading \\
\hline $0 \%-35 \%$ & Difficult & Frustration level \\
\hline
\end{tabular}

Table 2 Cloze guide to comparisons of comprehension (Source: Jones 1997)

The literature identifies several limitations of Cloze tests. McKamey (2006) finds that Cloze tests may function differently for different language groups. A reader's prior knowledge is the key variable in comprehension and a Cloze test provides a means to measure how an 'average' reader actually understands key sections of written material (Fanguy et al. 2004). Therefore, a Cloze test is only a proxy measure to capture the average reader's comprehension (Fanguy et al. 2004). Despite these limitations, linguists prefer the test due to its simplicity and ease of interpretation (McKamey 2006).

\section{Aim and Objectives}

The literature review shows that traditional construction contracts lack clarity and this could lead to issues of interpretation and comprehension. However, most studies used opinion surveys and other qualitative methods to arrive at this conclusion. The literature review also shows that standard forms have become complex and difficult to read in their successive editions. This claim is not verified by an objective criterion and there is no clear evidence regarding clarity improving comprehension. Therefore, clarity and its relationship to comprehension of contract conditions remains an understudied area. To overcome this shortfall, the present study analyses the clarity of contract conditions and their comprehension using objective measures that have been developed in the field of linguistics. The study focuses on the second to the most recent editions of Fédération Internationale des Ingénieurs-Conseils (FIDIC) Conditions of Contract for Works of Civil Engineering (FIDIC 1969; FIDIC 1977; FIDIC 1987; FIDIC 1999). FIDIC has a suite of contracts and the Conditions of Contract for Works of Civil Engineering is popularly known as the Red Book. To achieve the above aim, this study devised the following three objectives:

1. To measure the clarity of the FIDIC Red Book from the second to the most recent editions in order to test the hypothesis that standard forms have become complex over time.

2. To measure the comprehension level of clauses in the FIDIC Red Book latest edition (FIDIC 1999) that were related to disputes. 
3. To establish the relationship between readability and comprehension to test the hypothesis that improved readability increases comprehension of a contract clause.

\section{Research Methods}

The basis of the study was the FIDIC Conditions of Contract Red Book. The first edition of the FIDIC Conditions of Contract (International) for Works of Civil Engineering was published in 1957. The second (FIDIC 1969), third (FIDIC 1977) and fourth (FIDIC 1987) editions followed. FIDIC 1987 dropped 'international' from its title (FIDIC 1987; Rameezdeen \& Rajapakse 2007). Most recently FIDIC 1999 saw a major change in the layout, text and title (FIDIC 1999; Bunni 2005). The title was changed to Conditions of Contract for Building and Engineering Work - Designed by Employer and is called New Red Book. The study analysed the last four editions of FIDIC in order to obtain the following measures of clarity on a clause-by-clause basis (or sub-clause as appropriate). The methodology used for this stage was a specific type of quantitative content analysis similar to the analysis by Raj et al. (2009). All clauses of the four FIDIC versions were analyzed using these quantitative content analysis tools.

1. Flesch Reading Ease Score (FRES)

FRES $=206.835-(1.015 \times$ ASL $)-(84.6 \times$ ASW $)$

Where,

$A S L=$ Average sentence length (the number of words divided by the number of sentences)

ASW $=$ Aaverage number of syllables per word (the number of syllables divided by the number of words)

2. Average Sentence length (ASL)

Sentence length measures the number of words in a sentence as in formula 2. The running texts of each clause were counted for words from period to period. This gives the average sentence length for each clause of the standard conditions.

$\mathrm{ASL}=\frac{N W}{N S}$

Where,

$\mathrm{NW}=$ Number of words in a clause

NS $=$ Number of sentences in a clause

3. Average Packet Length (APL)

Packet length refers to the number of words between any syntactical punctuation marks in a clause. Zero counts caused by adjacent punctuation marks have been excluded. Hyphenated words, abbreviations, acronyms, and quantities were counted as one word. The punctuation marks used were full-stops, commas, colons, semi-colons, exclamation marks, question marks, long dashes and parentheses. The measure gives the average packet length of each clause.

$\mathbf{A P L}=\frac{\mathrm{NW}}{\mathrm{NP}}$

Where,

$\mathrm{NW}=$ Number of words in a clause

$\mathrm{NP}=$ Number of packets in a clause

An interview survey was conducted with 11 experts who have more than five years' experience in construction dispute resolution and dealt with FIDIC 1999 at least twice. The objective was to find the FIDIC 1999 clauses that related to contractual disputes. The sampling was based on peer selection of professionals from the industry (snowball 
sampling) who routinely worked in dispute resolution and are familiar with contracts based on FIDIC conditions (Robson 2011). The interviewees were asked to identify frequently referred contract clauses in disputes and rank them in the descending order of frequency. The purpose of the interview survey was to reduce the number of clauses used in the subsequent Cloze test. A Cloze test is time-consuming and all clauses of FIDIC 1999 cannot be subjected to it. Therefore, only a sub-set of clauses, the most relevant in terms of disputes, were selected.

Cloze test has a structured procedure that must be followed so that comprehension level of a text can be measured in an objective manner. In total, 30 professionals from the industry who had experience working with FIDIC conditions participated in the Cloze test (refer Table 3 for the participant profile). These participants were selected using Purposive Sampling methodology. They were asked to fill the missing words of each clause as per the standard Cloze test guidelines. The test was administered in a place that was convenient for the respondents (most were done in their offices) but in front of the Research Assistant so that it was similar to a closed-book examination environment. The average Cloze scores were obtained for these clauses as a measure of comprehension.

\begin{tabular}{|c|c|}
\hline Category & Number of participants \\
\hline Quantity Surveyor & 24 \\
\hline Project Manager & 3 \\
\hline Engineer & 2 \\
\hline Architect & 1 \\
\hline Total & 30 \\
\hline
\end{tabular}

Table 3 Profile of professionals who took part in the Cloze test

\section{Results}

As discussed above, the current and all previous editions of the FIDIC Red Book, except the very first edition were subjected to different measures of clarity. These measures were obtained for all clauses of the Standard Conditions and the results are summarized in Tables 5-7. The tables clearly indicate that the most recent edition, FIDIC 1999, is the easiest to read having the highest average FRES, lowest average sentence length and lowest average packet length.

To understand how difficult it is to read a Standard Condition, the FRES values obtained from the study have to be viewed in the light of comparable readability levels. Table 8 gives the percentages of clauses belonging to each readability level for the four documents under consideration. It shows that even the easiest document among them, FIDIC 1999, contains $95 \%$ of clauses which have college level readability or above. More than $50 \%$ of its clauses are 'very difficult' to read which is equivalent to postgraduate level.

\begin{tabular}{|c|c|c|c|c|}
\hline Descriptive statistic & $\begin{array}{c}\text { FIDIC 1969 } \\
(n=119)\end{array}$ & $\begin{array}{c}\text { FIDIC 1977 } \\
(n=142)\end{array}$ & $\begin{array}{c}\text { FIDIC 1987 } \\
(n=175)\end{array}$ & $\begin{array}{c}\text { FIDIC 1999 } \\
(n=165)\end{array}$ \\
\hline Median & 21.1 & 22.9 & 22.3 & 28.9 \\
\hline 1st Quartile & 12.1 & 13.0 & 11.4 & 22.5 \\
\hline 3rd Quartile & 31.8 & 33.5 & 35.15 & 37.2 \\
\hline
\end{tabular}

Table 5 Distribution of FRES values of FIDIC clauses

\begin{tabular}{|c|c|c|c|c|}
\hline Descriptive statistic & $\begin{array}{c}\text { FIDIC 1969 } \\
(\mathrm{n}=119)\end{array}$ & $\begin{array}{c}\text { FIDIC 1977 } \\
(\mathrm{n}=142)\end{array}$ & $\begin{array}{c}\text { FIDIC 1987 } \\
(\mathrm{n}=175)\end{array}$ & $\begin{array}{c}\text { FIDIC 1999 } \\
(\mathrm{n}=165)\end{array}$ \\
\hline Median & 56 & 50 & 40 & 24 \\
\hline 1st Quartile & 39 & 33 & 24 & 16 \\
\hline 3rd Quartile & 83 & 78 & 63 & 36 \\
\hline
\end{tabular}

Table 6 Distribution of Average Sentence Length of FIDIC clauses

Rameezdeen, R and Rodrigo, A (2013) 'Textual complexity of standard conditions used in the construction industry', Australasian Journal of Construction Economics and Building, 13 (1) 1-12 


\begin{tabular}{|c|c|c|c|c|}
\hline Descriptive statistic & $\begin{array}{c}\text { FIDIC 1969 } \\
(n=119)\end{array}$ & $\begin{array}{c}\text { FIDIC 1977 } \\
(n=142)\end{array}$ & $\begin{array}{c}\text { FIDIC 1987 } \\
(n=175)\end{array}$ & $\begin{array}{c}\text { FIDIC 1999 } \\
(n=165)\end{array}$ \\
\hline Median & 28 & 12 & 10 & 8 \\
\hline 1st Quartile & 13 & 6 & 6 & 5 \\
\hline 3rd Quartile & 49 & 21 & 18 & 14 \\
\hline
\end{tabular}

Table 7 Distribution of Average Package Length of FIDIC clauses

\begin{tabular}{|c|l|c|c|c|c|}
\hline \multirow{2}{*}{ FRES } & \multirow{2}{*}{ Difficulty level } & \multicolumn{4}{|c|}{ Percentage of clauses } \\
\cline { 3 - 6 } & FIDIC 1969 & FIDIC 1977 & FDIC 1987 & FIDIC 1999 \\
\hline $0-30$ & Very difficult & 71.7 & 66.9 & 72.2 & 53.6 \\
\hline $30-50$ & Difficult & 25.8 & 29.8 & 21.8 & 41.0 \\
\hline $50-60$ & Fairly difficult & 2.5 & 3.3 & 3.6 & 3.6 \\
\hline $60-70$ & Standard & - & - & 1.8 & 1.2 \\
\hline $70-80$ & Fairly easy & - & - & 0.6 & 0.6 \\
\hline $80-90$ & Easy & - & - & - & - \\
\hline $90-100$ & Very easy & - & - & - & - \\
\hline
\end{tabular}

Table 8 Readability levels of FIDIC clauses

The second objective of this study was to measure comprehension levels of clauses of FIDIC 1999 identified as frequently referred in disputes by an expert panel. The clauses identified (see Table 9) generally matched with the results of similar studies elsewhere (lyer et al. 2002; Seifert 2005). This enabled the Cloze test to be performed on only 20 clauses as opposed to all the clauses of FIDIC 1999. The average Cloze values of the 20 clauses were between 49.2-65.2, as given in Table 9, with the clause 'Employer's Entitlement to Termination' being the easiest to comprehend while the clause dealing with 'Programme' proved to be the most difficult. There were 6 clauses belonging to the 'easy' level of comprehension while the rest found to be at the 'standard' level. It is interesting to note that none of the identified clauses were at the 'difficult' level of comprehension.

\begin{tabular}{|c|l|l|}
\hline Clause number & \multicolumn{1}{|c|}{ Title } & Cloze score \\
\hline Easy & \multicolumn{2}{|c|}{} \\
\hline 15.5 & Employer's Entitlement to Termination & 65.2 \\
\hline 8.8 & Suspension of Work & 64.4 \\
\hline 8.10 & Payment for Plant and Materials in Suspension & 64.1 \\
\hline 14.8 & Delayed Payment & 63.6 \\
\hline 14.6 & Issue of Interim Payment Certificates & 62.2 \\
\hline 8.1 & Commencement of Works & 61.5 \\
\hline Standard & & 59.6 \\
\hline 12.4 & Omissions & 59.6 \\
\hline 13.3 & Variation Procedure & 59.4 \\
\hline 20.1 & Contractor's Claims & 58.1 \\
\hline 8.6 & Rate of Progress & 57.5 \\
\hline 13.1 & Right to Vary & 57.3 \\
\hline 12.3 & Evaluation & 56.7 \\
\hline 14.9 & Consequences of Suspension & 56.3 \\
\hline 14.7 & Application for Interim Payment Certificates & 54.6 \\
\hline 8.4 & Payment & 52.9 \\
\hline 8.5 & Extension of Time for Completion & 52.8 \\
\hline 8.2 & Delays Caused by Authorities & 51.1 \\
\hline 16.2 & Time for Completion & 50.4 \\
\hline 8.3 & Termination by Contractor & 49.2 \\
\hline
\end{tabular}

Table 9 Mean Cloze scores of FIDIC 1999 clauses that are related to construction disputes $(\mathrm{n}=30)$

Rameezdeen, R and Rodrigo, A (2013) 'Textual complexity of standard conditions used in the construction industry', Australasian Journal of Construction Economics and Building, 13 (1) 1-12 
The third objective was to establish the relationship between readability and comprehension in order to test the hypothesis that improved readability increases comprehension of a contract clause. To operationalize this research question, Pearson's Correlation Coefficient was used as the measure of association to express the extent to which the two variables, FRES and Cloze scores, were related. The value of Pearson's Correlation Coefficient ( $r$ ) vary between +1 and -1 . Both extremes represent a perfect relationship and 0 absence of a relationship (Tan 2002).

$\mathrm{r}=\frac{\mathrm{N} \sum \mathrm{XY}-\left(\sum \mathrm{X}\right)\left(\sum \mathrm{Y}\right)}{\sqrt{\left[\mathrm{N} \sum \mathrm{X}^{2}-\left(\sum \mathrm{X}\right)^{2}\right]\left[\mathrm{N} \sum \mathrm{Y}^{2}-\left(\sum \mathrm{Y}\right)^{2}\right]}}$

Where;

$$
\begin{aligned}
& \mathrm{N}=\text { Number of subjects } \\
& X=\text { FRES score } \\
& \mathrm{Y}=\text { Cloze score }
\end{aligned}
$$

The direction of the relationship is indicated by the sign of the Correlation Coefficient. A positive sign indicates that high scores of one variable tend to be associated with high scores of the other. A ' $r$ ' value of +0.165 was obtained between Cloze and the relevant FRES scores of the clauses under consideration. It implies that when the readability level of a clause is high it is easier to comprehend. However, the strength of the relationship is weak, indicating that there may be other factors influencing comprehension such as prior knowledge, experience, etc.

\section{Discussion}

The study used quantitative measures to demonstrate that FIDIC 1999 is the most successful document compared to its predecessors with regard to ease of reading. Nevertheless, it requires a minimum of college level reading skills to comprehend $46 \%$ of its clauses. More than $50 \%$ of its clauses are found to be 'very difficult', which is equivalent to postgraduate level. The above findings are consistent with the findings of Bunni (2003, p.9), who reports that only $4 \%$ of the population could comprehend about $86 \%$ of the FIDIC 1977 clauses. Bunni (2003, p.9) places the readability level of FIDIC equivalent to an IQ level of 130 or above. This IQ level equates to a 'difficult' level of standard FRES (Mason and Morris, 2000). The results of the present study show that about $96 \%$ of FIDIC 1977 clauses are within this level of readability.

According to Ali and Wilkinson (2010, p. 326), experts suggest 20 words or less per sentence is ideal for clarity. However, the present study finds that the four FIDIC editions having an average of 56, 50, 40 and 24 words per sentence respectively. Bunni $(2003$, p.9) observes that $86 \%$ of FIDIC 1977 sentences are of more than 28 words. A study by Raj et al. (2009, p.217) discovered that the average sentence length of the FIDIC White Book was 32 for the first three editions published between 1990 and 1998, increasing to 34 in its latest edition published in 2006. Ali and Wilkinson (2010, pp. 332-333) show a GC/Works/1 and JCT Design and Build Contract clauses with 156 and 134 words, respectively, in a single sentence with a FRES score of 0 .

Is this status quo conducive for the wellbeing of the construction industry? Does the contract document inhibit communication between parties to a contract? These questions are particularly pertinent to the construction industry where parties to the contract, client and contractor, are laymen when it comes to legal scholarship (Rhys Jones 1994; Ali \& Wilkinson 2010). The parties are supposed to sign and agree on matters they can read and comprehend. While both parties might have support from professionals familiar with these documents, the parties themselves nevertheless need to be fully aware of their rights and 
obligations prior to the signing of a contract. Unfortunately, FIDIC has failed to provide a readable and understandable document to its users. In terms of the first hypothesis of the study, the results clearly demonstrate that the readability levels of FIDIC have increased over its successive editions. It provides a clue that the drafters are beginning to understand the necessity of clarity in their document and that future editions could be expected to be clearer and simpler than the current edition. The results, therefore, do not support the hypothesis that successive editions are more complex and difficult to read.

In defence of the present status quo with regard to clarity, one could argue that plain language does not suit a narrative that requires a very specific meaning to be conveyed to the reader (Cornes 1996). Cornes (1996) contends that use of plain language could blur legal certainty. Perry (1995) observes that it can cause lack of precision and legal scrutiny required for a legal document. Plain language can bore people and make them lose the significance of a clause (Broome \& Hayes, 1997). The other reason for maintaining the status quo stems from familiarity and precedence (Broome \& Hayes, 1997). With the use of Standard Conditions, practitioners become familiar with its strengths and weaknesses. In addition, a long trail of precedence can guide a practitioner to better comprehension of the document.

Nevertheless, there seems to be enough room to reduce the difficulty of reading by enhancing the readability of FIDIC documents. A good move in this regard could be observed in the increased readability levels of the NEC/ECC contract clauses (Perry 1995; Broome \& Hayes 1997; Rameezdeen \& Rajapakse 2007). NEC is a standard contract specifically developed with a focus on reducing legalese and the drafting of plain easy to read language structure. A comparison of summary readability statistics of FIDIC 1999 and NEC 1993 obtained from one of our previous studies is given in Table 10. It clearly shows that NEC is a smaller document with better language structure and readability.

If there is potential to improve communication as a result of increased readability, it is the responsibility of the drafting committee of these documents to look into this aspect seriously in future editions (Raj et al. 2009; Ali \& Wilkinson 2010). However, the literature review shows there is a lack of understanding about the benefits of improved clarity on the comprehension of a contract clause. In order to shed some light on this issue, the present study tested the hypothesis that improved readability increases comprehension of contract clauses. The result supports the hypothesis but the relationship between readability and comprehension was found to be weak.

\begin{tabular}{|l|c|c|}
\hline \multicolumn{1}{|c|}{ Description } & FIDIC & NEC \\
\hline Counts & 158,024 & 41,870 \\
Number of characters & 29,891 & 8,248 \\
Number of words & 860 & 309 \\
Number of sentences & 1.50 & 1.40 \\
\hline Averages & 28.90 & 22.10 \\
Sentences per paragraph & 5.10 & 4.90 \\
Words per sentence & & \\
Characters per word & 29.70 & 40.70 \\
\hline Readability & \\
\hline FRES
\end{tabular}

Table 10 Summary readability statistics of FIDIC and NEC (Source: Rameezdeen \& Rajapakse 2007)

\section{Conclusions}

FIDIC 1999 emerged as having the highest average readability level with the lowest Average Sentence Length and Average Packet Length among all FIDIC editions. The average FRES value of FIDIC 1999 is around 29, whereas the other three documents have a value of 2123. This shows that FIDIC 1999 is the easiest to read of the four editions. Nevertheless, $54 \%$ 
and $41 \%$ of its clauses are of postgraduate and college level readability, respectively. Taken together, about $95 \%$ of clauses need at least college level reading skills to comprehend the document. The hypothesis that standard forms have become complex over the years was not supported by this study. In fact successive standard forms have become easier to read. It verifies the self-stated claim of drafters of the latest edition that they wanted to make FIDIC 1999 easier to read than the previous editions. The association between FRES and Cloze scores was found to be directly proportional, with a weak relationship proving the hypothesis that improved readability increases the comprehension of a contract clause.

\section{References}

Ali, N.A.N.A. and Wilkinson, S. (2010) 'Modernising construction contract drafting - a plea for good sense'. Proceedings of the 18th CIB World Building Congress, 10-13 May, Salford, United Kingdom, 323-345

Bresnen, M. and Marshall, N. (2000) 'Partnering in construction: a critical review of issues, problems, and dilemmas', Construction Management and Economics, 18, 229-237

Broome, J. C. and Hayes, R.W. (1997) 'A comparison of the clarity of traditional construction contracts and of the New Engineering Contract', International Journal of Project Management, 15, 255-261

Broome, J.C. and Perry, J.G. (1995) 'Experiences of the use of the New Engineering Contract', Engineering, Construction and Architectural Management, 2, 271-285

Bubshait A.A. and Almohawis, S.A. (1994) 'Evaluating the general conditions of a construction contract', International Journal of Project Management, 12,133-136

Bunni, N. G. (2003) Risk and insurance in construction, Spon Press, London

Bunni, N. G. (2005) The FIDIC form of contract, Third ed., Blackwell, Oxford

Calderỏn, J.L., Morales, L.S., Liu, H., and Hays, R.D. (2006) 'Variation in the readability of items within surveys', American Journal of Medical Quality, 21, 49-56

Candlin, C.N., Bhatia, V.K., and Jensen, C.H. (2002) 'Developing legal writing material for English second language learners: problems and perspectives', Journal of English for Specific Purposes, 2, 299-320

Cheung, S.O. and Yiu, T.W. (2006) 'A study of construction mediator tactics - part I: Taxonomies of dispute sources', IEEE Transactions on Engineering Management, 53, 456470

Cheung, S.O. and Yiu, T.W. (2007) 'Are construction disputes inevitable?', Building and Environment, 42, 752-761

Chong, H. Y. and Zin, R.M. (2010) 'A case study into the language structure of construction standard form in Malaysia', International Journal of Project Management, 28, 255-261

Chong, H. Y., Balamuralitharan, B. and Chong, S.C. (2011) 'Construction contract administration in Malaysia using DFD: A conceptual model', Industrial Management \& Data Systems, 111, 1449-1464

Cornes, D. (1996) 'The second edition of the New Engineering Contract', International Construction Law Review, 13, 97-119

Courtis, J.K. (1998) 'Annual report readability variability: tests of the obfuscation hypothesis', Accounting, Auditing and Accountability Journal, 11, 459-471

DuBay, W.H. (2004) The principles of readability, Impact Information, California

Emmitt, S. And Gorse, C. (2003) Construction communication, Blackwell, London

Fanguy, R., Kleen, B.A. and Soule, L.C. (2004) 'Privacy policies: cloze test reveals readability concerns', Issues in Information Systems, 5, 117-123 
FIDIC (1969) Conditions of Contract for Works of Civil Engineering Construction, Second ed., Fédération Internationale des Ingénieurs-Conseils, Geneva

FIDIC (1977) Conditions of Contract for Works of Civil Engineering Construction, Third ed., Fédération Internationale des Ingénieurs-Conseils, Geneva

FIDIC (1987) Conditions of Contract for Works of Civil Engineering Construction, Fourth ed., Fédération Internationale des Ingénieurs-Conseils, Geneva

FIDIC (1999) Conditions of Contract for Building and Engineering Works- Designed by the Employer, First ed., Fédération Internationale des Ingénieurs-Conseils, Geneva

Glick, A., Taylor, E.D.D., Valenza, J.A. and Muhammad, F.W. (2010) 'Assessing the content, presentation, and readability of dental informed consent', Journal of Dental Education, 74, 849-861

Greene, E., Fogler, K. and Gibson, S.C. (2012) 'Do people comprehend legal language in wills?', Applied Cognitive Psychology, 26, 500-507

Haapio, H. (2011) 'Contract clarity through visualization: preliminary observations and experiments', Proceedings of the $15^{\text {th }}$ International Conference on Visualization, IEEE Computer Society, 13-15 July, London

Hall, J.C. (2006) 'The readability of original articles in surgical journals', ANZ Journal of Surgery, 76, 68-70

Harmon, K.M.J. (2003) 'Resolution of construction disputes: a review of current methodologies', Leadership and Management in Engineering, 3, 187-201

Harrison, S. and Bakker, P. (1998) 'Two new readability predictions for the professional writer: pilot trials', Journal of Research in Reading, 21, 121-138

lyer, C. K., Satyanarayan, K.N. and Ganesh, L.S. (2002) 'Dispute prone contract clauses - a basis for operational flexibility in contract administration', Global Journal of flexibility systems Management, 4, 55-63

Jergeas, G.F. and Hartman, F.T. (1994) 'Contractors' construction-claims avoidance', Journal of Construction Engineering and Management, 120, 785-795

Jones, M.J. (1997) 'Methodological themes - critical appraisal of the cloze procedure's use in the accounting domain', Accounting, Auditing and Accountability Journal, 10, 105-128

Kennedy, P., Morrison, A. and Milne O. (1997) 'Resolution of disputes arising from set-off clauses between main contractors and subcontractors', Construction Management and Economics, 15, 527-537

Kintsch, W. (1988) 'The role of knowledge in discourse comprehension: a constructionintegration model', Psychological Review, 95, 163-182

Koo, M.M., Krass, I. and Aslani, P. (2003) 'Factors influencing consumer use of written drug information', The Annals of Pharmacotherapy, 37, 259-267

Mason, J. and Morris, L. (2000) 'Improving understanding and recall of the probation service contract', Journal of Community and Applied Social Psychology, 10, 199-210

Masson, M.E.J. and Waldron, M.A. (1994) 'Comprehension of legal contracts by nonexperts: Effectiveness of plain language redrafting', Applied Cognitive Psychology, 8, 67-85

McKamey, T. (2006) 'Getting closure on Cloze: a validation study of the rational deletion', Second Language Studies, 24, 114-164

McLaughlin, G.H. (1969) 'SMOG grading - a new readability formula', Journal of Reading, 22, 639-646

Ndekugri, I., Smith, N. and Hughes, W. (2007) 'The engineer under FIDIC's conditions of contract for construction', Construction Management and Economics, 25, 791-799 
Orlow, M.K.P., Taylor, H.A. and Brancati, F.L. (2003) 'Readability standards for informedconsent forms as compared with the actual readability', The New England Journal of Medicine, 348, 721-726

Paz, S.H., Liu, H., Fongwa, M.N., Morales, L.S. and Hays, R.D. (2009) 'Readability estimates for commonly used health-related quality of life surveys', Quality of Life Research, 18, 889-900

Perry, J.G. (1995) 'The new engineering contract: principles and design of risk allocation', Engineering, Construction and Architectural Management, 2, 197-208

Raj, S., Hilling, J. and Hughes, W. (2009) 'Responsiveness to change by standard-form contract drafters in the construction industry: A case study of the FIDIC White Book', International Journal of Law in the Built Environment, 1, 205-220

Rameezdeen, R. and Rajapakse, C. (2007) 'Contract interpretation: the impact of readability', Construction Management and Economics, 25, 729-737

Rhys Jones S. (1994) 'How constructive is construction law?', Construction Law Journal, 10, 28-38

Robson, C. (2011) Real world research: A resource for users of social research in applied settings, Third edition, John Wiley, London

Russell, D.R. (2007) 'Rethinking the articulation between business and technical communication and writing in the disciplines: useful avenues for teaching and research', Journal of Business and Technical ommunication, 21, 248-277

Rutherford, B.A. (2003) 'Obfuscation, textual complexity and the role of regulated narrative accounting disclosure in corporate governance', Journal of Management and Governance, 7, $187-210$

Seifert, B.M. (2005) 'International construction dispute adjudication under international federation of consulting engineers conditions of contract and the dispute adjudication board', Journal of Professional Issues in Engineering Education and Practice, 131, 149-157

Smith, M. and Taffler, R. (1992) 'Readability and understandability: different measures of the textual complexity of accounting narrative', Accounting, Auditing and Accountability Journal , 5, 84-98

Stamboltzis, A. and Pumfrey, P. (2000) 'Reading across genres: a review of literature, Support for Learning, 15(2), 58-61

Sydserff, R. and Weetman, P. (2002) 'Developments in content analysis: a transitivity index and DICTION scores', Accounting, Auditing and Accountability Journal, 15, 523-545

Tan W. (2002) Practical Research Methods, Prentice Hall, Singapore

Thomas, H.R., Smith, G.R. and Mellot, R.E. (1994) 'Interpretation of construction contracts', Construction Engineering and Management, 120, 321-336

Valentine, D.G. (1992) 'How not to draft a contract', The International Construction Law Review, 9, 526-529

van den Broek P., Rapp, D.N. and Kendeou, P. (2005) 'Integrating memory-based and constructionist processes in accounts of reading comprehension', Discourse Processes, 39 (2\&3), 299-316

Velez, P. and Ashworth, S.D. (2007) 'The impact of item readability on the endorsement of the midpoint response in surveys', Survey Research Methods, 1 (2), 69-74

Wang, W.C. and Yang, J.B. (2005) 'Applications of electronically facilitated bidding model to preventing construction disputes', Automation in Construction, 14, 599-610

Wright, J.N. and Fergusson, W. (2009) 'Benefits of the NEC ECC form of contract: A New Zealand case study', International Journal of Project Management, 27, 243-249 